\title{
Shifting to food industry self-monitoring may be hazardous
}

Published at www.cmaj.ca on Sept. 16, 2008.

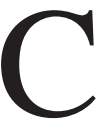

ontamination in a Canadian meat processing plant may no longer automatically result in a shutdown, according to a leaked chapter of the Canadian Food Inspection Agency's proposed procedures manual for meat hygiene.

Rather, companies are to develop and implement an "action plan" in response to the contamination. The leaked document - "Chapter 18: Compliance Verification System" also indicates the government has not yet resolved how it will conduct biological tests of industry facilities and equipment. It is among a number of chapters still listed as unavailable at the food inspection agency's website (www.inspection.gc.ca). An agency spokesperson says some of the documentation is under revision.

The unpublished chapter, leaked to $C M A J$, states that upon receiving a request from the agency, companies must take corrective measures by "Providing an acceptable action plan by a specified date" and "Effectively implementing the corrective and preventative measures as described in the action plan by a specified date."

The changes, which took effect in April 2008, have dismayed meat inspectors, particularly the fact that they can no longer take immediate action to clean up contaminated plants, says the head of the union for federal food safety inspectors.

"Instead of [inspectors] shutting down the line, now they just fill out Corrective Action Requests," says Bob Kingston, president of the Agricultural Union of the Public Service of Alliance of Canada. That request includes "some kind of response to how they plan to deal with it."

There is confusion, says Kingston, about how long companies have to perform these tasks and about the conditions under which they will be compelled to notify inspectors of problems.

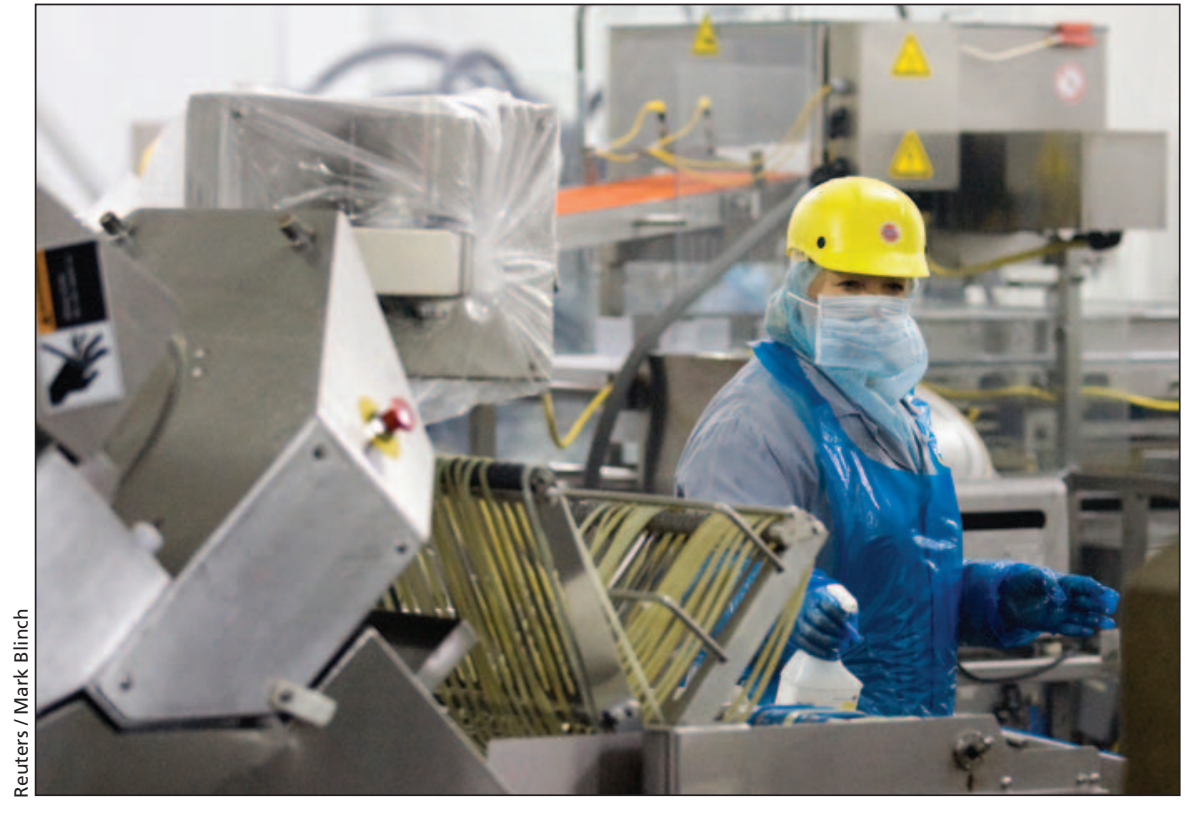

A woman endeavours to sterilize meat processing and packaging equipment the Maple Leaf Foods plant in Toronto, Ontario, at which meat products were produced that were recalled after being linked to the listeriosis outbreak.

Perhaps even more significantly, Kingston says there is also confusion about how often inspectors are to take samples from meat products for microbiological testing.

Under the heading "CFIA Sampling," the leaked chapter describes microbiological requirements as being "currently under development."

The old protocols dictated the frequency of testing for different microbes. For Listeria, the microbe responsible for the recent outbreak at an Ontario Maple Leaf Foods plant that has killed at least 16 Canadians, the agency's manual stated: "Sampling is conducted at a minimum frequency of twice per year."

Kingston is unsure whether that still applies. "That's the debate."

That debate and others over the ambiguities of the new inspection system lie at the core of an ongoing controversy over food safety which has erupted in the wake of the deadly listeriosis outbreak that, as of CMAJ's Sept. 15, 2008, press deadline, had caused 14 deaths in Ontario, 1 in Alberta and 1 in British Columbia.

At the heart of the controversy lies the issue of who should bear the bulk of responsibility for inspecting meat.

Some believe it's the Canadian Food Inspection Agency. But many food safety experts, who seem generally agreed that the ongoing global shift toward industry self-monitoring is long overdue, say food companies should bear responsibility because they are more motivated to ensure their products are safe. Harming customers, after all, is very bad for business.

The agency favours industry monitoring, and has drawn sharp criticism for pulling meat inspectors off plant floors, where they conduct visible inspections, and making them spend more time in the office, where they examine industry-collected safety data.

The agency says the new system will ensure food companies adhere to the principles of Hazard Analysis at Critical Control Points (HACCP), an international production control system designed to reduce risks. 
Critics claim the move will only result in more breakdowns like the one at Maple Leaf Foods.

For its part, the federal government has essentially deferred the issue and hopes to deflect public anger by ordering an "independent investigation" into the outbreak. Its terms of reference include a review of "the efficiency and effectiveness of the response of the federal organizations."

The agricultural union has blamed the government, accusing it of slashing funding for food safety programs by nearly $30 \%$, to $\$ 254$ million in fiscal year 2010/11 from $\$ 359$ million in 2006/07.

Still, many food safety researchers believe the shift toward more industry involvement in inspection was inevitable and will result in a more scientifically based - and ultimately more effective — food safety system.

"The government is trying to monitor as much as possible, but it just can't," says Sylvain Charlebois, a food distribution and safety researcher and associate dean of the graduate school of business at the University of Regina. "We are dealing with such a vast and complex system. You need a viable and functional partnership between government agencies and the industry or else it's just not going to work."

Many countries have already given industry a greater role in food inspection. The US Government Accountability Office recently studied the food safety networks of 6 countries: Canada, Germany, Ireland, Japan, the Netherlands and the UK. In a June 2008 report, it claims the "burden for food safety in most of the selected countries lies primarily with food producers, rather than with inspectors, although inspectors play an active role in overseeing compliance."

The prevailing argument against governments getting out of the inspection game is that private companies, concerned more with bottom lines than customers' health, will do little inspection or may even, if they have something to hide, fudge test results.

"The counter argument is that firms have strong private incentives to produce safe food and will do so anyway, and this movement from carcass-by-carcass inspection to overseeing a HACCP plan is more efficient," says Julie Caswell, an expert in international food systems and chair of the Department of Resource Economics at the University of Massachusetts Amherst.

The economic research division of the US Department of Agriculture favours the latter argument.

In a 2003 report, International Trade and Food Safety, it states that private companies have strong financial incentives to prevent food crises: "Firms implicated in a crisis may suffer from reputation lost, stock prices reduced, plants closed for cleanup or permanently shut down, food poisoning lawsuits filed, premiums raised for product liability insurance, and demand for product reduced enough to threaten entire markets or industries."

Some food safety researchers believe private companies are also more likely to create new testing technologies and safety protocols. This could result in an increased reliance upon microbiological testing, as opposed to the century-old visible inspection model, which some critics deride as the "pokeand-sniff" method.

"I've yet to find a human being who can use their eyes to see salmonella or listeria or E. coli," says Marc Richard, a Canadian Food Inspection Agency spokesperson. "Instead of looking at meat and not seeing the microbes, inspectors will be looking at test results."

But the public perception, Richard suggests, is that more bodies is better than more data. He likens the inspection agency's role in the food industry to that of police officers enforcing speed limits. The public, he says, sees things differently. "For some reason, in food, people expect the policemen to be driving the cars."

Michael Batz, executive director of the Food Safety Research Consortium and head of food safety programs at the University of Florida's Emerging Pathogens Institute, also believes the future of food safety lies in sophisticated data analysis systems.

The current US system, similar to Canada's, relies heavily on inspectors who scan thousands of carcasses for visible signs of disease or distress.
This, he suggests, leads to a system dominated by "off-the-cuff" judgments and outbreak damage control.

Richard understands, however, why the public is wary of pulling inspectors off plant floors. "A chicken covered in salmonella looks the same as a chicken not covered in salmonella ... but when you talk about taking eye balls off the birds it just feels like a bad idea to many people," he says.

There are risks, of course, to adopting a system in which private companies collect safety data and federal inspectors review it. Inspectors may not be qualified to perform sophisticated scientific analysis of the data or, as has been the case in Canada since the new system's introduction, they will be overwhelmed with paperwork and confused by vague guidelines. While companies at risk of being penalized may fake test results.

But the biggest risk, according to Batz, is that the government might receive limited access to important information. "With federal inspectors, the data is in-house. If private firms are involved, who owns the data and where does it sit? Does government have full access? Is there some shielding, and will industry only have to report if they pass or fail?"

Many future food safety systems, some researchers claim, will likely be private-public hybrids. Firms with good track records will receive more freedom; those with poor track records will receive more scrutiny - the end goal being the most effective mix of private monitoring and government policing. Still, no amount of testing and inspection will remove all risks.

"What you need, whether it's at a farm or a processor or a slaughter house or a retailer - whoever is dealing with the food at that point - is to have a culture of food safety, where they are thinking about his stuff 24/7," says Doug Powell, head of the International Food Safety Network, a repository of food safety-related information at Kansas State University. "It is much more than just testing and inspecting. It's really having people get religion about this stuff." - Roger Collier, CMAJ

DOI:10.1503/cmaj.081459 